\title{
Psychological Effects of COVID-19 on Nurses in Kuwait Hospitals \& The Efficiency of Coping Mechanism Including Graduate from Nursing Institute
}

\author{
Narjes A Alherz \\ Nursing Tutor, Nursing Institute, Public Authority for Applied Education and Training, Kuwait, \\ PO box 23778, Kuwait City, Kuwait \\ na.alherz@paaet.edu.kw
}

\begin{abstract}
By the end of November 2020, the total death of COVID-19 in Kuwait hospitals reached 880 persons in a country of 4.137 million population comparing to 1.46 million death word wide. This pandemic has rapidly and profoundly affected every part of daily life, from the way people work, live, shop, socialize, and plan for future. In this battle, nurses were the big fighter against this enemy and went through tremendous psychological \& physical pressure, working long shifts and often not provided with adequate emotional support (Veenema\& Meyer,2020) under these conditions, the WHO recognizes the importance of nurse's mental health and wellbeing. Therefore, nurses need supportive psychological interventions to promote emotional release and improve their mental health, hoping to overcome this stage safely with sturdy psychological health.Purpose: In this study, I am trying to highlight the level of the psychological impact of this event on our staff nurses in Kuwait hospitals\& the efficiency of their coping mechanism during this pandemic with special consideration to the reaction of graduate nurses from Kuwait nursing institute.Method: In this quantitative method survey, an online questionnaire using Google Form was distributed through the head of the department in designated hospitals for COVID-19 between November 7 and 16 -2020 snowball sampling technique was also encouraged, a total of 187 nurses were responded in this sample, uncompleted questionnaires were excluded.The questionnaire included four main sections, social- demographic information, occupational \& work history, general health questionnaire (GHQ-12), and a simplified copping style scale.A consent form was available pre- to filling the survey, Participant could withdraw at any point they wish even after an agreement to start.Results: A total of 181 participants attended the study, 79.6\% Female while 20.4\% were Male 30identified as having psychological distress. 151 were without destress, univariate analysis revealed that there is significant difference in nationality, job role, working years, effectiveness of available precautionary measures, being treated differently because of working in hospital \& being in contact with covid-19 cases between the two groups. Number of Kuwaiti staff without destress is less than their number with destress.For the two types of copping style, the mean avoidant coping of those with distress (2.49) was higher than that without distress (2.07) this difference was statistically significant where $\mathrm{p}=0.00$ Approach coping for the destress group is higher than approach coping of the nondistress group, Approach coping for our institute graduate was higher than the avoidant coping.Conclusions: Our staff nurses in Kuwait hospitals have a low psychological effect due to COVID-19 outbreak with variable coping style, our nursing institute graduate experience allow psychological effect \& a positive coping mechanism. coping style is divided to approach \& avoidant style, approach style is much stronger.
\end{abstract}

Keywords: COVID-19- Pandemic - nurses- nursing institute graduate- Psychological distress- Coping style

DOI: $10.7176 / \mathrm{JHMN} / 91-02$

Publication date:July $31^{\text {st }} 2021$

\section{INTRODUCTION:}

COVID-19 is an infectious disease caused by a newly discovered virus that was first reported on December 12 , 2019, in Wuhan (Wang, Tang, \&Wei,2020: Zhou et al.,2020a) affecting 218 countries with a total of 65.868 .826 infected cases \& 1.517.524 death sword wide (WHO), In Kuwait, the total numbers of cases reached 143.917 cases \& 886 deaths.

The first case in Kuwait was discovered on the 24 Feb coming from Iran (Republic of Kuwait Ministry of health,2020) all the batch being isolated to guaranty the non-spread of the virus, most infected cases were recovered spontaneously without special treatment, whereas the minority labeled as severe cases usually chronic diseases \& elderly (WHO, 2020)

Coronavirus counted as one of the fast-spreading diseases heading toward middle and elderly age population causing death for elderly \& chronic disease cases.

In the middle of this dramatic battle the brave solder -our frontline nurses fighting to ensure an acceptable level of care, sacrificing their time\& safety for their patients. Despite the increased number of infected cases among the health professionals in Kuwait and around the ward Staff nurses are still sincerely working, day to day their social isolation builds up and more psychological distress could be noticed (Kang et al., 2020). 
Psychological distress is a state of emotional suffering associated with stressors and demands that are difficult to cope with in daily life, the lack of effective care for and difficulty in identifying psychological distress is frustrating for health professionals, it may indicate the beginning of major depressive disorder

Our staff nurses are in daily contact with infected cases, anxious about the safety of their own \& their family, looking forward to the end of this pandemic.

In this study, I am trying to portray the psychological impact levels of nurses due to this outbreak, and the effectiveness of their coping style including our graduate staff from the nursing institute.

\section{DESIGN}

Quantitative method survey through online questionnaire link was shared through WhatsApp, information about the survey was provided to the head of some department with the questionnaire link then to different groups all over the hospital, each staff is requested to read the clarification provided before the agreement to start. The questionnaire started with 5 personal questions, 11work history questions, 2 medical history questions, psychological effect -12 questions \&12 question coping mechanisms.

\section{PARTECIPANT:}

187 participants from the front line of different department in Kuwait hospitals (ICU, Causality, COVID-19 ward, OPD\& clinics) started the questionnaire, only 181 completed the questionnaire 144Female \& 37 Male, 88 staff aged 30-39, and 66 were between40-49,21were less than 30 years old\& 3 only above age of 60 years. majority were non-Kuwaiti 149, married153, with educational level of bachelor's degree 88, Diploma degree 69, Associated degree (nursing institute graduate) 20 .data were daily examined to exclude the non-completed answers (paper was excluded if more than five answer was messing).

\section{INSTRUMENT:}

The 12-item General Health Questionnaire (GHQ-12) (Goldberger \& Williams,1988) consists of 12 items (6positive\&6negative) to assess the mental health, positive items corrected not at all answer (3degree) to 0 degree for much more than usual answers. On the other hand, negative items corrected as 3 degree for much more than usual answer and 0 for not at all answer, the total score range was between $0-42$, the higher score indicate the presence of psychological distress.

On the other hand, Brief- COPE from Novo Psych2018 (with modification-12 items) was used as a tool to assess coping style which presented either as avoidance coping or approach coping.

Avoidance Coping or negative coping characterized by behavioral disengagement, self-blame \&denial this group are less effective at dealing with distress, each item in the negative coping scores from(1)for (haven't been doing this at all) to (4) for I have being doing this a lot, on the other hand approach or positive coping personal characterized by ability to plane, accept, seek emotional\& informational support so they are more effective in dealing with distress with the same scoring from(1)for haven't been doing this at all, to (4) for I have being doing this a lot .one religion question was included but not counted as approach nor avoidance coping.

Data analysis:( Statistical methodology)

Data were collected and coded, entered to IBM compatible computer, using the SPSS version 26 for Windows. Entered data were checked for accuracy then for normality, using Kolmogorov-Smirnov \& Shapiro-Wilk tests, and proved to be normally distributed. Qualitative variables were expressed as number and percentage while quantitative variables were expressed as median, mean $(\overline{\mathbf{X}}) \&$ standard deviation (SD). The arithmetic mean was used as a measure of central tendency, while the standard deviation (SD) was used as a measure of dispersion.

The following statistical tests were used:

1-The $\chi 2$-test (or likelihood ratio $=$ LLR) was used as a non-parametric test of significance for comparison between the distribution of two qualitative variables.

2-The Fisher's exact test was used as a non-parametric test of significance for comparison between the distribution of two qualitative variables whenever the $\chi 2$-test was not appropriate. It gives a p-value directly.

3-Independent samples t-test was used as a test of significance for comparison between comparison between the mean score of avoidant and approach coping regarding those with and without stress, after performing the Levine's test for equality of variances.

4-Paired samples t-test was used as a test of significance for comparison between the mean score of avoidant and approach coping together.

A 5\% level is chosen as a level of significance in all statistical significance tests used.

RESULT:

From 07November-16 November 2020, a total of 189 electronic questionnaire were collected, 8partecipation 
were excluded because of not completing the questionnaire properly. ended with 181 that included in the study. response rate was estimated to about $94.76 \%$, reliability of $\mathrm{GHQ}=0.685$, reliability of coping $=0.759$ participants characteristics

Total of 181 participants, $(n=144$ female $-79.6 \%) \&(n=37$ male $-20.4 \%)$, 88where between the age of 30-39, non-Kuwaiti were the majority $(143-79.0 \%),(\mathrm{n}=153-84.5 \%)$ married, most of them with bachelor's degree (48.6\%-n88) majority were staff nurse (134-74.0\%), area of causality-emergency counted for $(n=33-33.7 \%)$ of total participant, the majority of staff working years were 10years or more $(n=106-58.6 \%)$ (Table 1$)$.

Table 1: Socklemographic characteristics of the front line nurses (unlvarlate enaysis)

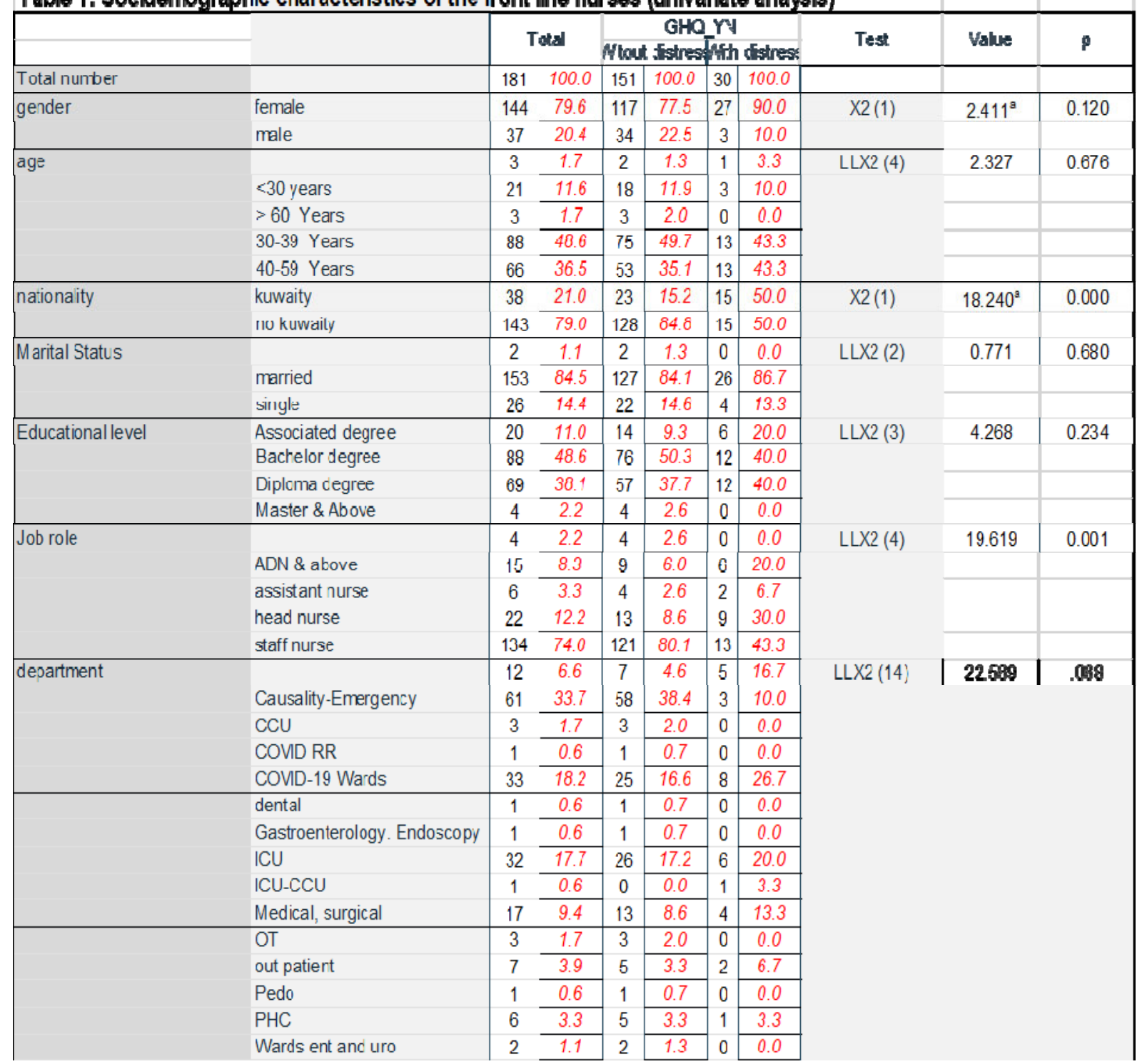


Table 1a: Socidemographic characteristics of the front line nursing institute graduate (univariate anaysis)

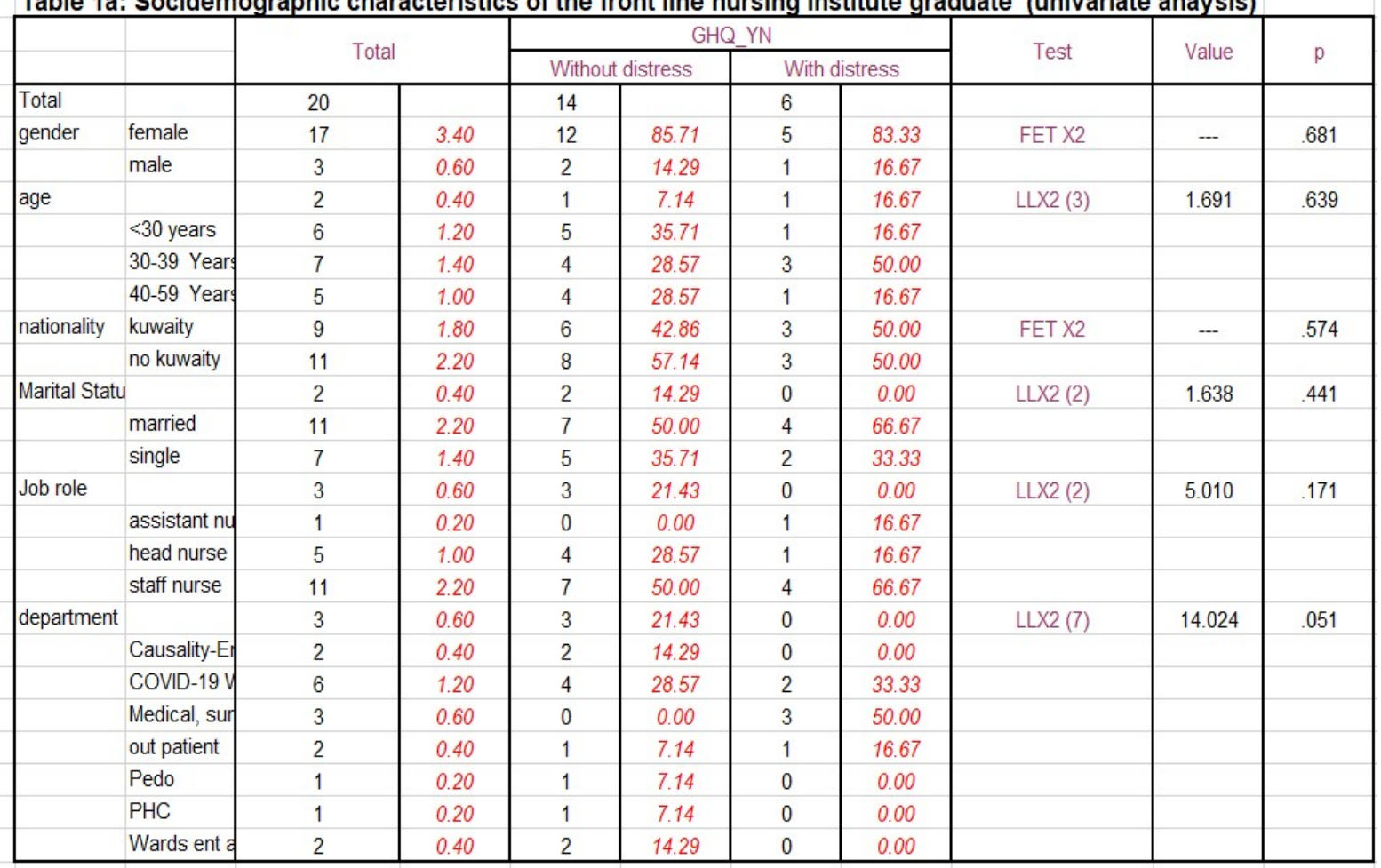

Occupational \&work history

Our staff nurses agreed that there were changes in their regular job duties(n=120-66.3\%), on the other hand $(\mathrm{n}=99-54.7 \%)$ stated that they did not work overtime.

Regarding the availability of PPE ( $\mathrm{n}=140-77.3 \%)$ informed that it is available \&28disagree, majority clarified those precautionary measures are effective $(n=134-74.0 \%)$ while 34 disagree. total of $(n=165-91.2 \%)$ being in contact with COVID-19, leading to $(n=118-65.2 \%)$ very concerned of own being infected, $(n=153-84.5 \%)$ very concerned of family being infected. (Table2).

Table2: Work- related characteristics\& concerned about COVID-19 of front-line nurses (universal analysis)

\begin{tabular}{|c|c|c|c|c|c|c|c|c|c|c|}
\hline & & & & & & & & & & \\
\hline & & \multirow{2}{*}{\multicolumn{2}{|c|}{ Total }} & \multicolumn{4}{|c|}{ GHQ YN } & \multirow{3}{*}{ Test } & \multirow{3}{*}{ Value } & \multirow{3}{*}{$\mathrm{p}$} \\
\hline & & & & \multicolumn{2}{|c|}{ Without distress } & \multicolumn{2}{|c|}{ With distress } & & & \\
\hline Total & & 20 & & 14 & & 6 & & & & \\
\hline \multirow[t]{7}{*}{ working years } & & 1 & 0.20 & 0 & 0.00 & 1 & 16.67 & LLX2 (6) & 12.298 & .056 \\
\hline & $>=10$ years & 1 & 0.20 & 1 & 7.14 & 0 & 0.00 & & & \\
\hline & $1-3$ years & 4 & 0.80 & 1 & 7.14 & 3 & 50.00 & & & \\
\hline & 10 years or more & 6 & 1.20 & 4 & 28.57 & 2 & 33.33 & & & \\
\hline & 12 & 1 & 0.20 & 1 & 7.14 & 0 & 0.00 & & & \\
\hline & 4-9 years & 3 & 0.60 & 3 & 21.43 & 0 & 0.00 & & & \\
\hline & less 1 year & 4 & 0.80 & 4 & 28.57 & 0 & 0.00 & & & \\
\hline \multirow[t]{3}{*}{$\begin{array}{lr}\text { Changes } & \text { of } \\
\text { regular } & \text { job } \\
\text { duties } & \\
\end{array}$} & & 1 & 0.20 & 1 & 7.14 & 0 & 0.00 & LLX2 (2) & 1.181 & .554 \\
\hline & no & 5 & 1.00 & 4 & 28.57 & 1 & 16.67 & & & \\
\hline & yes & 14 & 2.80 & 9 & 64.29 & 5 & 83.33 & & & \\
\hline \multirow[t]{2}{*}{$\begin{array}{l}\text { working } \\
\text { overtime }\end{array}$} & no & 9 & 1.80 & 7 & 50.00 & 2 & 33.33 & FET X2 & --- & .426 \\
\hline & yes & 11 & 2.20 & 7 & 50.00 & 4 & 66.67 & & & \\
\hline \multirow[t]{2}{*}{$\begin{array}{l}\text { Personal } \\
\text { Protective } \\
\text { Equipment are } \\
\text { available }\end{array}$} & no & 3 & 0.60 & 2 & 14.29 & 1 & 16.67 & FET X2 & --- & .681 \\
\hline & yes & 17 & 3.40 & 12 & 85.71 & 5 & 83.33 & & & \\
\hline
\end{tabular}




\begin{tabular}{|c|c|c|c|c|c|c|c|c|c|c|}
\hline \multirow[t]{3}{*}{$\begin{array}{l}\text { Available } \\
\text { Precautionary } \\
\text { measures are } \\
\text { effective }\end{array}$} & & 1 & 0.20 & 0 & 0.00 & 1 & 16.67 & LLX2 (2) & 2.538 & .281 \\
\hline & no & 4 & 0.80 & 3 & 21.43 & 1 & 16.67 & & & \\
\hline & yes & 15 & 3.00 & 11 & 78.57 & 4 & 66.67 & & & \\
\hline \multirow[t]{3}{*}{$\begin{array}{ll}\begin{array}{l}\text { Being treated } \\
\text { differently } \\
\text { because } \\
\text { working } \\
\text { hospital. }\end{array} & \\
\end{array}$} & & 1 & 0.20 & 1 & 7.14 & 0 & 0.00 & LLX2 (2) & 4.244 & .120 \\
\hline & no & 4 & 0.80 & 4 & 28.57 & 0 & 0.00 & & & \\
\hline & yes & 15 & 3.00 & 9 & 64.29 & 6 & 100.00 & & & \\
\hline \multirow[t]{2}{*}{$\begin{array}{l}\text { Being in contact } \\
\text { with COVID-19 } \\
\text { cases }\end{array}$} & no & 4 & 0.80 & 4 & 28.57 & 0 & 0.00 & FET X2 & --- & .207 \\
\hline & yes & 16 & 3.20 & 10 & 71.43 & 6 & 100.00 & & & \\
\hline \multirow[t]{3}{*}{$\begin{array}{l}\text { Concern of own } \\
\text { being infected } \\
\text { with COVID-19 }\end{array}$} & a little concerned & 5 & 1.00 & 3 & 21.43 & 2 & 33.33 & LLX2 (2) & 1.728 & .421 \\
\hline & not concerned & 4 & 0.80 & 2 & 14.29 & 2 & 33.33 & & & \\
\hline & very concerned & 11 & 2.20 & 9 & 64.29 & 2 & 33.33 & & & \\
\hline \multirow[t]{3}{*}{ 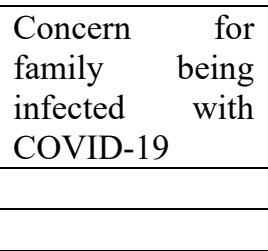 } & a little concerned & 2 & 0.40 & 0 & 0.00 & 2 & 33.33 & LLX2 (2) & 5.884 & .053 \\
\hline & not concerned & 1 & 0.20 & 1 & 7.14 & 0 & 0.00 & & & \\
\hline & very concerned & 17 & 3.40 & 13 & 92.86 & 4 & 66.67 & & & \\
\hline
\end{tabular}

Table 2a: Work-related characterstics and concerned about COVID-19 of the front line nursing istitute graduate (univariate anaysis)

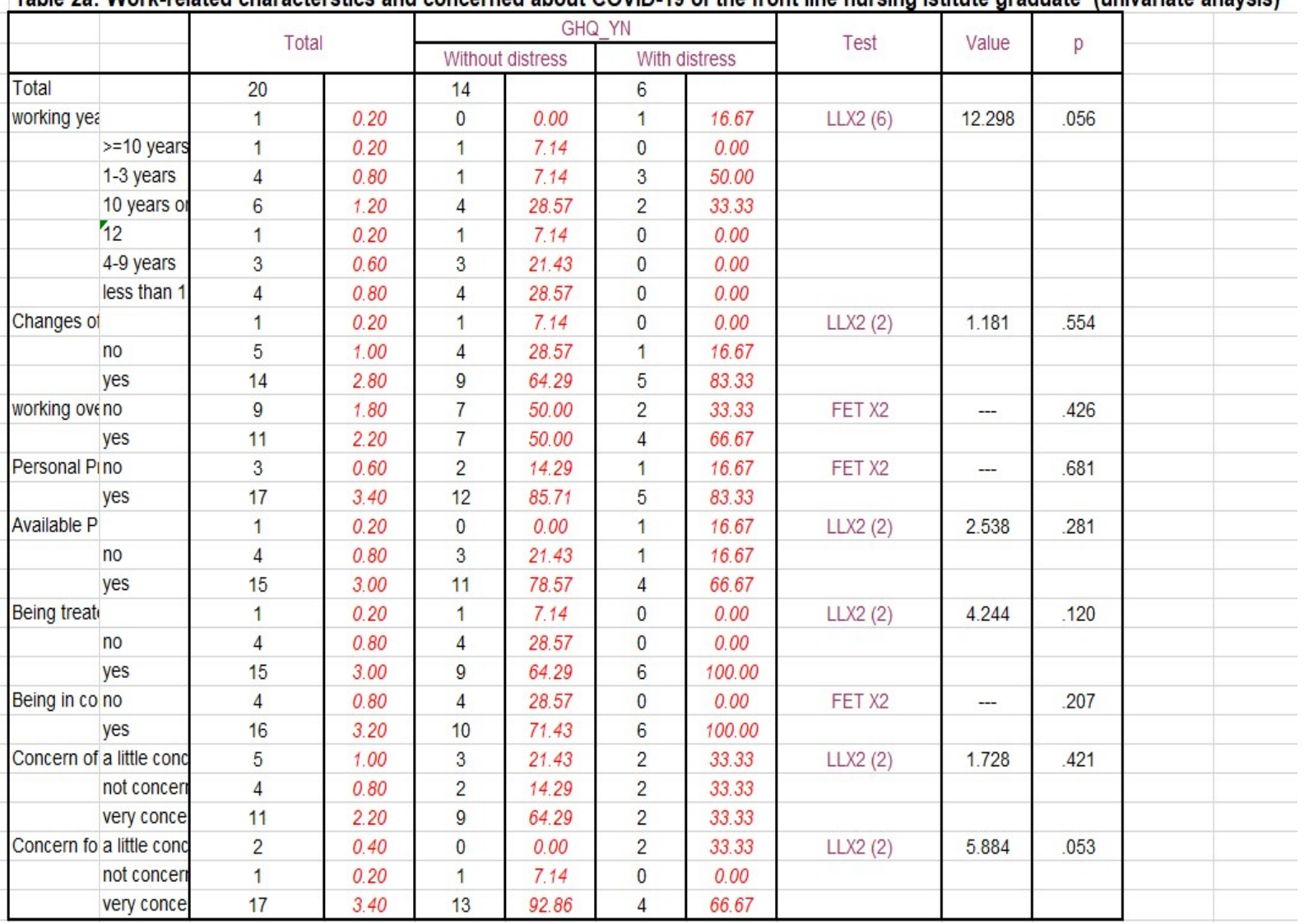




\section{Health history}

Among 181 participant 44complain of headache (24.3\%), varicose veinin30personale (16.6\%),24diagnosed as hypertension (13.3\%), 19 with respiratory problems (10.5\%) \&18 diabetes mellitus $(9.9 \%), 69 \%$ on regular treatment. (Table 3) clarify the relation of the most common diseases with GHQ 12 finding.

\section{Table (3): Distribution of the first five leading symptoms by GHQ12 findings}

\begin{tabular}{|c|c|c|c|c|c|c|c|c|c|}
\hline \multirow[b]{3}{*}{ Headache } & \multirow{3}{*}{$\begin{array}{c}\text { Total } \\
44\end{array}$} & \multicolumn{5}{|c|}{ GHQ_YN } & \multirow{3}{*}{$\frac{\text { Test }}{\text { LLX2 (2) }}$} & \multirow{3}{*}{$\begin{array}{l}\text { Value } \\
4.695\end{array}$} & \multirow{3}{*}{$\begin{array}{c}p \\
.096\end{array}$} \\
\hline & & & \multicolumn{2}{|c|}{ Without distress $n=151$} & \multicolumn{2}{|c|}{ With distress $n=30$} & & & \\
\hline & & 24.3 & 32 & 21.2 & 12 & 40.0 & & & \\
\hline Varicose vein & 30 & 16.6 & 25 & 16.6 & 5 & 16.7 & $\operatorname{LLX2}(3)$ & .735 & .865 \\
\hline Hypertension & 24 & 13.3 & 18 & 11.9 & 6 & 20.0 & $\operatorname{LLX} 2(2)$ & 1.625 & .444 \\
\hline Respiratory proble & 19 & 10.5 & 12 & 7.9 & 7 & 23.3 & $\operatorname{LLX2}(2)$ & 5.500 & .064 \\
\hline Diabetes mellitus & 18 & 9.9 & 14 & 9.3 & 4 & 13.3 & $\operatorname{LLX2}(3)$ & 2.450 & .484 \\
\hline
\end{tabular}

General health questionnaire-12score.

Out of 181 staff 151 found to be without destress majority are female ( $\mathrm{n}=117-77.5 \%)$ while male counted for $(n=34-22.5 \%)$, Total of 30 personal only found to be under stress female $(n=27-90 \%)$, male $(n=3-10 \%)($ Table 1$)$

\section{Coping style:}

For staff nurses, mean score of avoidant coping among those with stress $(2.49+0.56)$ was significantly $(p<0.001)$ higher than that of those without stress $(2.07+0.56)$.

Although the mean score of approach coping among those with stress $(3.14+0.58)$ was higher than that of those without stress $(2.99+0.75)$, however, this difference was not statistically significant $(\mathrm{p}=0.330)$.

The mean score of approach coping was significantly higher than that of avoidant coping among those with stress and those without stress $(\mathrm{p}<0.001$, each).

Among the associated degree nurses $(n=20)$, the mean score of avoidant coping among those with stress $(2.69+0.88)$ was higher than that of those without stress $(2.21+0.51)$, however, this difference was not statistically significant $(\mathrm{p}=0.135)$.

Also, the mean score of approach coping among those with stress $(2.95+0.41)$ was higher than that of those without stress $(2.98+0.59)$, however, this difference was not statistically significant $(\mathrm{p}=0.913)$.

The mean score of approach coping was significantly higher than that of avoidant coping among those without stress $(p<0.001$, each). On the other hand, the mean score of approach coping was higher than that of avoidant coping among those with stress however, this difference was not statistically significant $(\mathrm{p}=0.609)$.

By tracing the group under stress $n=30$ we found that some were coping positively (approach coping) $3.14+-0.58$, some were negative in coping(avoidance) $2.49+0.56$, same for population without any stress $\mathrm{n}=146,2.07+\ldots .65$ coped negatively, 144 were positive in coping $2.99+0.75$. (Table 4)

For the group of nursing institute graduate it was clear that coping approach group $\mathrm{p}=.913$ exceed the number of avoidant coping $\mathrm{p}=.135$ (Table $4 \mathrm{a}$ )

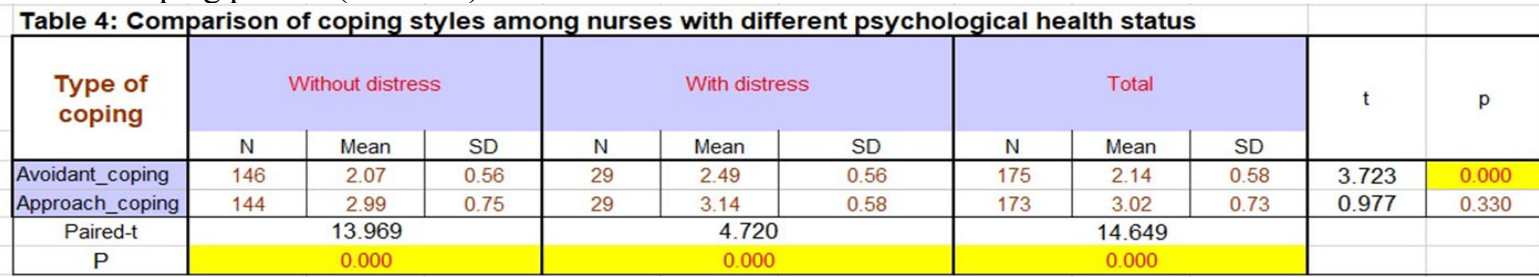

Table4 a: Comparison of coping styles among nursing institute graduate with different psychological health status

\begin{tabular}{|c|c|c|c|c|c|c|c|c|c|c|c|}
\hline \multirow{2}{*}{$\begin{array}{l}\text { Type of } \\
\text { coping }\end{array}$} & \multicolumn{3}{|c|}{ Without distress } & \multicolumn{3}{|c|}{ With distress } & \multicolumn{3}{|c|}{ Total } & \multirow{2}{*}{$t$} & \multirow{2}{*}{$p$} \\
\hline & $\mathrm{N}$ & Mean & $\mathrm{SD}$ & $\mathrm{N}$ & Mean & $\mathrm{SD}$ & $\mathrm{N}$ & Mean & $\mathrm{SD}$ & & \\
\hline Avoidant_coping & 14 & 2.21 & 0.51 & 6 & 2.69 & 0.88 & 20 & 2.35 & 0.65 & -1.566 & 0.135 \\
\hline Approach_coping & 14 & 2.98 & 0.59 & 5 & 2.95 & 0.41 & 19 & 2.97 & 0.54 & 0.111 & 0.913 \\
\hline Paired-t & \multicolumn{3}{|c|}{3.682} & \multicolumn{3}{|c|}{0.555} & \multicolumn{3}{|c|}{3.193} & & \\
\hline$P$ & \multicolumn{3}{|c|}{0.000} & \multicolumn{3}{|c|}{0.609} & \multicolumn{3}{|c|}{0.005} & & \\
\hline
\end{tabular}




\section{FINAL ANALYSIS}

From the 181-personal shared in the survey 151 were working with less psychological destress comparing ton $=30$ under stress, significant difference could be detected between the two groups of nationality personal, Kuwaiti nurses with destress are less than Kuwaiti nurses without destress. same could be noticed regarding the job role, staff nurses without distress are much more than those of non, moving to working years majority were of more than 10 years of experience \& the difference was significant between the stress\& non stress group, we could notice the big difference in both groups regarding to the effectiveness of PPE, being treated differently because of working in hospitals\& being in contact with infected cases (Table1,2)

For the type of copping style, significant difference could be detected for the group of avoidance copping between the two-part included, negative copping for group with stress is stronger than non-stress group.in comparing the general finding we notice that approach copping for stress group is higher than without distress.

\section{DISCUSSION:}

In this research it was disclosed that minority of our staff nurses including nursing institute graduate Experienced certain level of psychological distress, reflected by the score of their answers, only 30staff out of total 181 staff cleared to be negatively affected \& being under stress, majority were female $n=27$ only 3 were male, 26married , only 4 were single, they found to be in area such as COVID-19 Wards, ICU-CCU-Medical ,Surgical Ward, Outpatient\& PHC, 13 out of 30 were staff nurses with degree of BSN n=12,Diploman=12,n=6 Associated degree, half were Kuwaiti $n=15$ - same number for non-Kuwaiti. Their age ranged between 30-39 $n=13$, same number for group age of $40-59, \mathrm{n}=15$ with ten or more years of experience ,remaining were from deferent working years less than 10 years, $n=23$ stated that there was changes in their regular job duties\& working overtime, $10 \%$ agreed for the availability of the precautional measures, $20 \%$ only disagree for the effectiveness of the precautionary measures, $80 \%$ stated being treated differently because of the event, $96.7 \%$ were in contact with COVID-19 cases, $66.7 \%$ very concerned of own being infected $\$ 86.7 \%$ for family being infected.

One of the reasons for starting this questionnaire is to high light the psychological effect of the event on our white dress solder\& attract the attention of administration to focus on the problem and positively deal with it before it spread and become difficult to deal with. high and positive mentality is needed for our staff to continue caring for their patients, self\& family.

Providing true, continuous reassurance and enough rest period is crucial, our staff need to feel the positive support, need to be provided with fact for what is going on, respect their wish be part of decision making, insure the availability\& effectiveness of precaution measures.

Our staff need a period of relaxation \&peace which might be difficult to fulfil specially with the increment of cases number \& working hours. We need to do our best be strong, patient, scarify

For the best of all. hospital's management need to come out with ideas to relieve the pressure over her staff nurses like reducing shift hours \& increasing shift number to reduce working

hours, provide for brief periodic meeting for psychological support or even online to feel the importance of them self \& the interest of their superior, short classis run by specialist for effective ways to deal with crises and practice relaxing and breathing sessions.

Instruction for economic way to deal with supply need to be scheduled to keep enough supplies, reassure the staff for the effectiveness of the available of personal protective equipment and give continuous feedback for how to deal effectively with the event and protect your self

As a staff nurse it is difficult to be away from contact with COVID-19 patient as it is critical part of their job, but they could be protected by enough supplies of PPE \&hand hygiene.

The majority $n=151$ were found to be without destress according to the result analysis of their GHQ but found to be very concern of own \& family being infected with the disease, although majority being in contact with infected cases. Elevation of body immunity could be necessary for our staff to resist the virus; balanced nutrition \& periodic rest period is important.

We notice that out of 33 nurses working in Covid-19 ward 8 staff had destress which count to be the higher percentage comparing to emergency department were out of 61 staff 3 being under destress, ICU is another high area of destress. These two areas have higher level of work stress, face unknown number of cases, forced to deal with dying cases, these high-risk environments could answer why staff in this area more vulnerable to destress.

Staff working 10 years or more got the highest percentage of destress 15 out of total 30 , this group counted for the majority of our sample106 out of 181, middle age group, active found in almost all department, they face previous conditions, knew how serious the condition is and can predict the end result of the situation.24 0ut of 107 being treated differently in the group of destress cases which could be resulting of their direct \& daily contact with sick or infected cases ,they are dangerous carrier fore microorganism, people might avoid direct contact with them as a way to protect them self which lead to more stress more isolation. On the other hand, almost all the group under stress 29 out of 30 were in direct contact with an infected cases which might explain why they are under stress, that will also increase their concern about their family. special attention need to be 
given for the negative copping group , learn to be open mind, be close to family ,positive thinking, use prayer to feel more positive ,they need more attention from administration to over come this difficult period.

\section{LIMATATION:}

Although our respond rate was high sample size was relatively small, study was done at the beginning of the crisis and the real psychological status might be underestimated. Time span was relatively short, longer study need to be performed to reflect a more realistic result.

\section{CONCLUSION:}

This study revealed that psychological impact of covid -19 on our staff was limited, majority were working without destress, our graduate from nursing institute were coping positively comparing to the minority of the avoidance coping in the same batch. unexpected negative copping was found for both groups The difference between Avoidant copping for the stress group \& the non-stress group were significant. Positive coping group were less in number Nursing administrations need to continue giving psychological support, care for her staff, appreciate their effort, reward, and reassure.

\section{Relevance for clinical practice:}

Covid-19 result in ending the life of thousands with no break, staff nurses cannot withdraw or stop, all medical staff under threat and that small negative group will grow if not being supported, early detection for sign of burn out, destress need to be noticed and treated, to stop further lost for our staff nurses. Special consideration should be taken for supporting the new graduate from nursing institute and other nursing school, leaving new graduate unsupported will lead to lose them early, appreciate must be shown to all nursing staff who are sincerely providing there best for the sake of others.

\section{REFERENCES}

1.Anliu Nie Master, RN, Xiangfan Su Associate Professor, Wenjie Guan RN Jian Feng Lien (2020). Psychophysiological impact of COVID - 19 outbreaks on frontline nurses: Across sectional survey study.Journal of clinical nursing WILEY J Clin Nur's. 2020:294217-4226. WILEY online library.com/journal/Joan.

2.Ana V. Nickcevic. Marcantonio M. Spada (2020). The COVID-19 anxiety syndrome scale: Development \& psychometric properties journal of Elsevier psychiatry Research 292/2020. https://do.org/10.1016/113322.

3.Al Thobaity A, AL Shammari F nurses on the frontline against the COVID-19 Pandemic (2020). An integrative Review Dubai Medical Journal (1-29) https://do.org/10.1159/000509361.

4.Cherish Kay L. Pastor (2020). Sentiment Analysis on synchronous online delivery of instruction due to Extreme Community Quarantine in Philippines caused by COVID-19 Pandemic. Asian Journal of MultiDisciplinary Studies. Vol. 3, No1(2020). ISSN 2651 -6691. Asianjournal.org.

5.Daniel Kwasi Ahorsu. Chung-ling Lin, Vida Imani, Mohsen Safari, Mark D. Griffiths, Amir H S Pak pour (2020). The fear of COVID-19 scale: Development and initial validation. International Journal of Mental Health and Addiction. https://do.org/10.1007/s11469-020-00270-8.

6.Dyeing, Hu, Yu Kong, Wengang L, Qujing Han, Xin Zhang, Lixiazhu, Suweiwan, Zuofeng Liv, Qushen, Jinggiv Yang, Hong. g uhe, \& Jiemin zhu (2020). Frontline nurses burnout, anxiety, depression \& fear status \& their associated factors during the COVID-19 outbreak in Wuhan, China. A large-scale cross section study. Clinical Medicine 24(2020) 100424.https://creative.commons.org/licenses/by-NC-Nd/4.01).

7.Eddie son Pasay -an, PHD Exploring the vulnerability of frontline nurses to COVID-19 \& its impact on perceived stress. journal of Taibah University Medical Science 2020 15(s), 404409.https://doi.org/10.1016/j.j tumed.2020.07.003.

8.Jill Maben, Jackie Bridges (2020) COVID-19 supporting nurses psychological \&mental health journal of clinical nursing Wiley 2020,29: 2742-2750.Doi: 10-1111/join.15307. Wiley online library.com/journal/join.

9.Leodoroj, Labrague j RN \& Janet de los santos, RN (2020). COVID-19 Anxiety among frontline nurses. Predictive role of organizational support, personal resilience, and social support. Med Rx iv preprint Doi: https://doi.org/10.1101/2020.07.16.20141069.

10. Lee, S.A., Mathis, A, Job, MC, \& Papalardo, EA (2020), clinically significant fear and anxiety od COVID19. a psychometric examination of the corona virus anxiety scale. Psychiatry Research, 113112 .

11.Maben, J. \& bridges, J (2020) COVID-19 supporting nurses psychological \& mental health. journal of clinical nursing. Ahead of print https://doi.org/10.1111/join/5307.

12.Ho. Y. Deng, L, Zhang, L, Lang, Q, Liao, C, Wang, N \& Huang, H (2020) work stress among Chinese nurses to support Wuhan in fighting against COVID-19 epidemic. Journal of nursing management. Ahead of print https://doi.org/10.111/join.30.4.

13.Maben, J, Bridges, J (2020). COVID-19 supporting nurses psychological and mental health, journal of 
clinical nursing. Ahead of print https://doi.org/10.1111/join.15307.Lin,senfeng,Zheng,jaoDong, Rou, Yu, Yan, Xiaoqian. Wu, Li Zhang, Jun Ma \& Yong Zeng (2020). Psychological distress in shadow of the COVID-19 pandemic. Preliminary development. Psychiatry Research 291(2020) 113202.https://doi.org/10.1016/jPsychres.2020.113202

14. Matteo Hero, Giacomo Pretro Vigezzi\& Michele Gapraro (2020). Carlo signoelli: Anna done .2019- Novel corona virus survey: knowledge $\&$ attitudes of hospital staff of large Italian teaching hospital. Acta Biomed 2020: vol.91 supplement 3:29-34. Doi:10.23750/abm. v 91:3-S 9419; Anna Bacardi, Paola Nizzero.

15. Steven Taylor \& Gordon J.G A Symondson. 2020. Life in a post - pandemic world: what to expect of anxiety - related conditions and their treatment, journal of anxiety disorder 72(2020) 102231.https://doi.org/10.1016/J.Janxdis.2020.10223/.

16. Cortez PA Joseph sj, Das N; Bhandari SS; Shobi's. Tools to measure the psychological impact of the COVID-19 pandemic. What do we have in platter? Asian journal of psychiatry, Zaang2020,53:102371Doi: 10.1016/j.apj.2020.102371.

17.Sofia papa, Vasiliki Ntella \& Paraskevi Katsaounou. Prevalence of depression, anxiety \& insomnia among health care workers during the COVID-19 pandemic. A systematic review \& rateanalysis.https://www.ncbi.nim.nih.gov/pmc/articles/PM7206431.

18.Christopher Cheney (2020) new survey cause effect of coronavirus pandemic on nurse Practitioners.https:/www.healthleadersmedia.com/nursing/new-survey-gauges-effect-coronaviruspanademic-nurse-practitioners.

19.Sherman A. Lee, Amanda A, Mathis \& Emily A, Papalardo. (2020) clinically significant fear \& anxiety of COVID-19: A psychometric examination of the coronavirus Anxiety scale. Doi: 10.1016/j.psychres2020.113112.https://www.ncbin nim.nih.gov/pmc/articles/PMC7237368/.

20.Vivian Schutz. \& Mona Shuttle (2020). Impact of COVID-19. What does it mean for nurse \& health systems? Journal of psychosocial nursing and mental health services.2020;58(8)2.3. https://doi.org/10.3928/0279 3695-2020 0707-01.

21.Yasemin Erkul Aksoy \& Vesile Kocak. (2020) Psychological effects of nurses \& midwives due to COVID-19 outbreak. The case of Turkey archives of psychiatric nursing vol 34 issues. Doi: httpsdoi.org/10.1015/j. apnus, p427-433-october-1.2020.

22.Yuanyuan, MoMM, Lan, Deng. MM, Layan, Zhang, BM\& Qiu, Yan, Lang, MB. work stress among Chinese nurses to support Wuhan in fighting against COVID-19epidemic journal of nursing Management /vol 28, issues. https://doi.org/10.1111/jonm.13014.

23. Maria, del, Pilar Sanchez, Lopez \& Virginia Driesch. 2008. The 12-item general questionnaire (CHQ-12): Reliability external validity \& factor structure in the Spanish population. Pliothermal 2008 vol.20. n.4, pp.839-843.www.psicotherma.com.

24.International Council of nurses protecting nurses from COVID-19 a top priority: A survey of ICN'S national Nursing Associations (2020).

25. Anne, Masie. R \& Janet Anderson UK Nurses \& Mid wives ongoing concerns during COVID-19 (second of three survey). https://www.KCL.ac.UK/news/UK-nurses 7 midwives-ongoing-concerns-during-COVID-19.

26.Goldberg D, \& Williams' (1991). A user's guide to the General health Questionnaire, London: NFER-Nelson Publishing.

27.Kangetal, L. Kang, Y. Li, S.HU, M. Chen, C. Yang, B.X. Yang, Z. LIU. The mental health of medical workers in Wuhan, China dealing with the 2019 novel coronavirus. The Lancet Psychiatry, 7(3) (2020), article e14,10.1016/s2215-0366(20)30047-X.

28.Li Li, Wan, C., Ding, R., LIV, Y, Chen, J, Wu, z, D Fan Li, c (2015) Mental distress among Liberian medical staff working at the China Ebola Treatment unit. Across sectional Stay healthy \& Quality of life outcomes, 13,156, https://doi.org/10.1186/s12955-015-0341-2. 